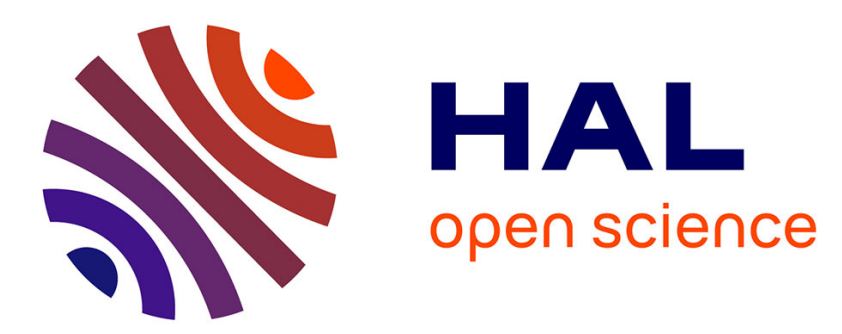

\title{
A Parisian Vision of the Chemistry of Hypercoordinated Silicon Derivatives
}

Gilles Lemière, Alexandre Millanvois, Cyril Ollivier, Louis Fensterbank

\section{To cite this version:}

Gilles Lemière, Alexandre Millanvois, Cyril Ollivier, Louis Fensterbank. A Parisian Vision of the Chemistry of Hypercoordinated Silicon Derivatives. Chemical Record, 2021, 21 (5), pp.1119-1129. 10.1002/tcr.202100049 . hal-03412875

\section{HAL Id: hal-03412875 https://hal.science/hal-03412875}

Submitted on 5 Nov 2021

HAL is a multi-disciplinary open access archive for the deposit and dissemination of scientific research documents, whether they are published or not. The documents may come from teaching and research institutions in France or abroad, or from public or private research centers.
L'archive ouverte pluridisciplinaire HAL, est destinée au dépôt et à la diffusion de documents scientifiques de niveau recherche, publiés ou non, émanant des établissements d'enseignement et de recherche français ou étrangers, des laboratoires publics ou privés. 


\section{A Parisian Vision of the}

\section{Chemistry of Hypercoordinated}

\section{Silicon Derivatives}

Gilles Lemière $^{*[a]}$, Alexandre Millanvois ${ }^{[a]}$, Cyril

Ollivier $^{*[a]}$, and Louis Fensterbank ${ }^{*[a]}$

Dedicated to Scott Sieburth, a visionary of silicon chemistry

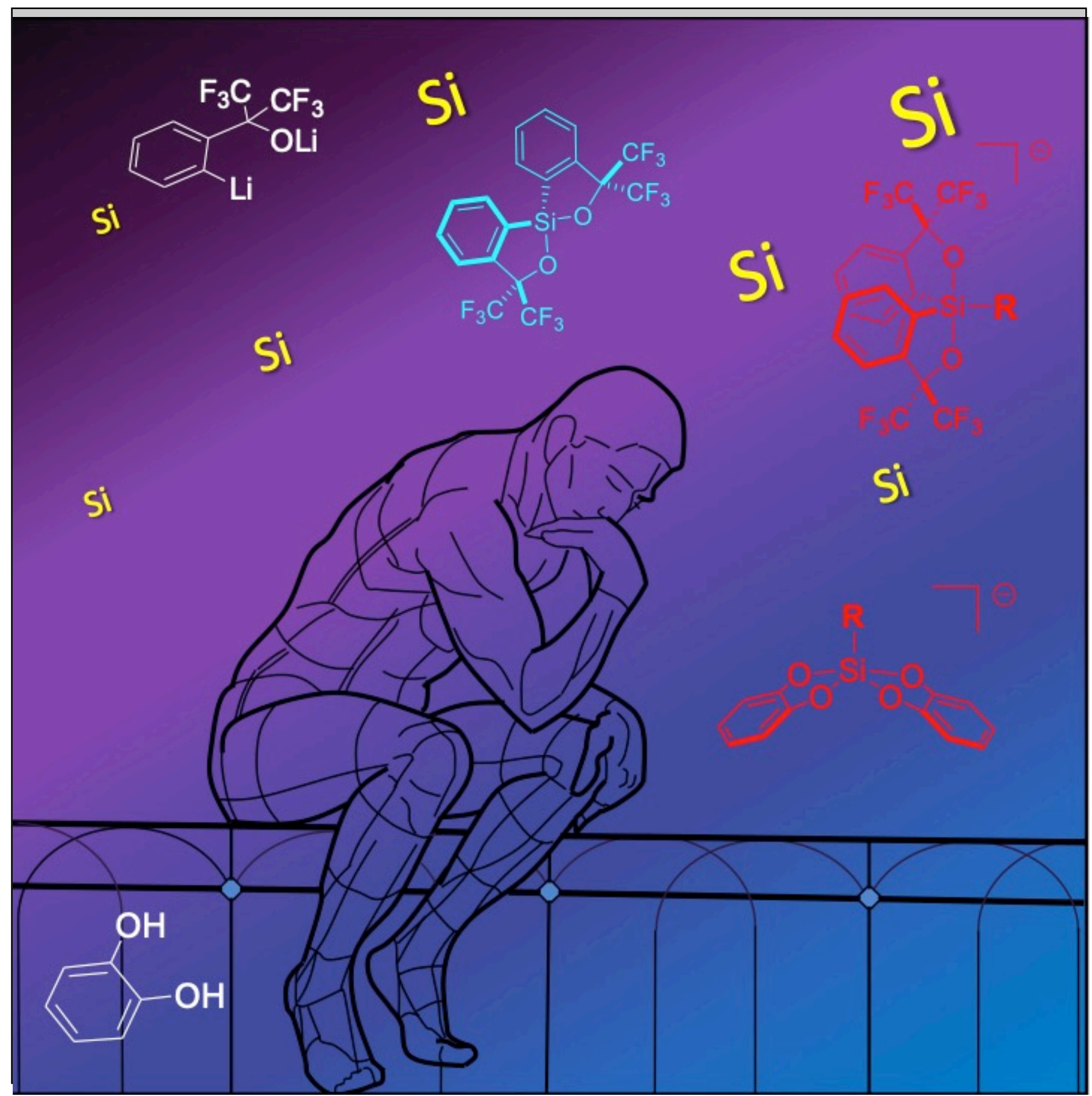


Abstract: Less than ten years of acquaintance with hypercoordinated silicon derivatives in our lab is described in this account. Martin's spirosilane derivatives open new opportunities as ligands and as agents for the activation of small molecules and bis-catecholato silicates have proven to be exquisite radical precursors in photoredox conditions for broad synthetic applications.

\section{Introduction: why hypercoordinated silicon derivatives?}

Just below carbon in the periodic table, silicon is much more than a pale imitation of carbon. While organosilicon compounds featuring a C-Si bond are very common, silicon, due to its lower electronegativity compared to carbon, the longer bonds by which it connects to neighboring atoms, its high affinity for fluoride and alkoxy ligands and its propensity to form hypercoordinated derivatives offers unique opportunities in organic chemistry. The first example of a hexavalent silicon derivative $\left(\mathrm{SiF}_{4} \cdot 2 \mathrm{NH}_{3}\right)$ was reported at the beginning of the $19^{\text {th }}$ century by Gay-Lussac and Davy. ${ }^{1}$ But it was the following century that saw the major discoveries that laid the foundations for the modern chemistry of hypercoordinated organosilicon compounds as conceptualized in the 1980 s by Voronkov, ${ }^{1}$ Holmes ${ }^{2}$ and Corriu ${ }^{3}$ just to name a few. ${ }^{4}$ As nicely highlighted in 2005 by Oestreich, ${ }^{5}$ the hypercoordinated mode can be transiently generated to trigger valuable reactivities such as the Brook rearrangement, the Tamao-Fleming oxidation or the Hiyama cross coupling just to name a few. But stable adducts can also be prepared, isolated and fully characterized. ${ }^{6}$ Our acquaintance with organosilicon compounds has a long history featuring arylsilanolates as metalation directing groups, ${ }^{7}$ silicon tethered Diels-Alder reactions, ${ }^{8}$ bromomethylsilyl ethers as precursors of radical cascades, ${ }^{9}$ epoxysilanes, ${ }^{10}$ silapiperidines. ${ }^{11}$ In this story, we will focus on two more recent stories. The first one deals with the use of Martin's spirosilane and derivatives as Lewis acids and their reactions toward various nucleophiles. The second one focuses on the introduction of bis-catecholato silicates as precursors of radicals in photooxidative conditions.

\section{Martin's spirosilanes as an entry for stable peculiar silicates}

\subsection{Martin's spirosilane, a valuable Lewis acid}

James Cullen Martin a.k.a. J. C. Martin is mainly known for his

[a] Dr. Gilles Lemière, Alexandre Millanvois, Dr. Cyril Ollivier and Prof. Louis Fensterbank

Institut Parisien de Chimie Moléculaire

Sorbonne Université, CNRS

4 place Jussieu, 75005 Paris

E-mail: gillles.lemiere@sorbonne-universite.fr,

cyril.ollivier@sorbonne-universite.fr, louis.fensterbank@sorbonneuniversite.fr invention of the Dess-Martin reagent. Nevertheless in 1979, he made a seminal report on the use of the dilithio derivative of hexafluorocumyl alcohol as a bidendate ligand that can be appended twice on heteroatoms such as phosphorus, sulfur and silicon to give the corresponding phosphoranoxide $\mathbf{1}$, sulfurane 2 and silicate $3 .{ }^{12}$ When treated with $\mathrm{SiCl}_{4}$, hexafluorocumyl alcohol dianion provides a direct access to spirosilane $\mathbf{4}$ that can also be obtained from the treatment of silicate $\mathbf{3}$ with triflic acid (Scheme 1). Due to the presence of the highly electronegative bis-trifluoro alkoxy ligand, spirosilane $\mathbf{4}$ is a very strong Lewis acid that can react with a variety of charged and neutral nucleophiles. ${ }^{13}$

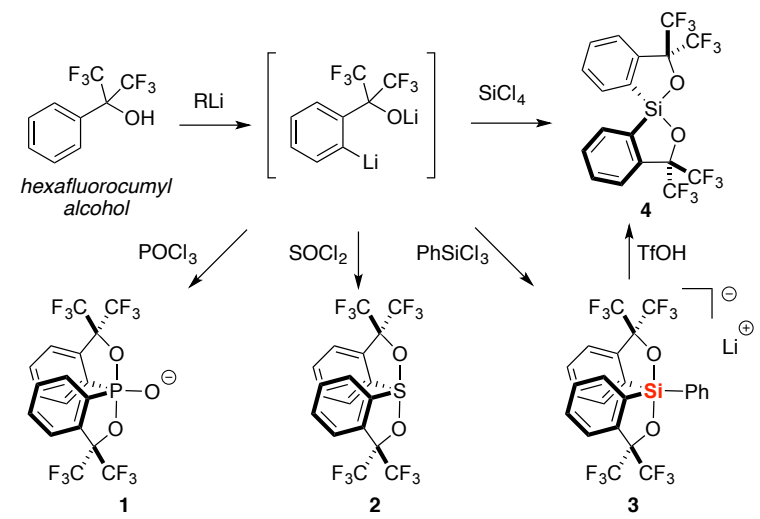

Scheme 1. Attachment of Martin's ligand on phosphorus, sulfur and silicon. Access to spirosilane 4

\subsection{Martin's spirosilane as a fluoride sensor}

For several years, our laboratory has been interested in the reactivity of Martin's spirosilanes $\mathbf{4}$ towards neutral or charged nucleophiles in order to obtain original structures. In particular, it was possible to exploit the Lewis acid properties and its ability to easily reach the hypercoordinated form, to use it as a fluoride probe (Scheme 2). ${ }^{14}$ The very strong Si-F bond warrants selective and quantitative detection of fluoride ions in solution and the structural reorganization of hypercoordinated silicon structure allows for a diagnostic.

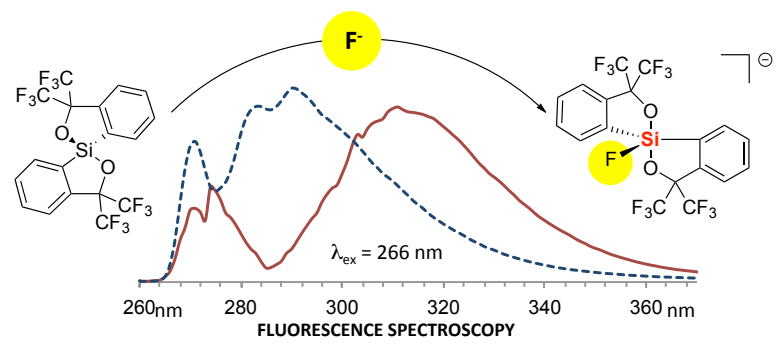

Scheme 2. Martin's spirosilane $\mathbf{4}$ as a fluoride sensor. 
UV and fluorescence spectroscopy have been used to quantify the fluorosilicate product attaining detection limits as low as 5 $\mu \mathrm{M}$ which is close to the residual concentration of fluoride in some drinking waters. Recently, Greb and coworkers have proposed a bis(alizarinato) spiro silane as chromogenic fluoride sensor which announces further developments in this area. ${ }^{15}$

\subsection{Interaction of Martin's spirosilane with N-heterocyclic carbenes (NHCs)}

Recently, we have studied the interactions of the Martin's spirosilane with neutral Lewis bases displaying various strength and steric hindrances. It has been established that the outcome of these interactions was very dependent on both parameters. ${ }^{16}$ Indeed, in the presence of weakly hindered NHCs Lewis base of imidazolylidene type (IMe, IMes), new neutral adducts $\mathbf{5}$ originating from classical Lewis acid-base interactions were obtained in which the pentacoordinated silicon adopts a trigonal bipyramid (TBP) geometry (Scheme 3), as highlighted by their $X$-ray diffraction (XRD) analyses. Conversely, when the size of the free carbene becomes larger (IPr, ItBu), no direct interaction between the silicon and the divalent carbon of the NHCs can be noticed by ${ }^{1} \mathrm{H}$ NMR monitoring. Considering the strength of the Lewis partners involved, the non-interaction is unambiguously diagnostic of Frustrated Lewis Pair (FLP) behaviors highlighting the bulkiness of the spirosilane to some extent. After some time, the mixtures evolves nonetheless towards the formation of an "abnormal adduct" $\mathbf{6}$ where a covalent bond is created between the silicon atom and one of the two trivalent carbons located on the NHC backbone. As it can be visualized on the XRD structure of $6(R=$ Dipp), the ligands surrounding the hypercoordinated silicon are quite distorted due to the steric congestions and deviates from the perfect TBP.

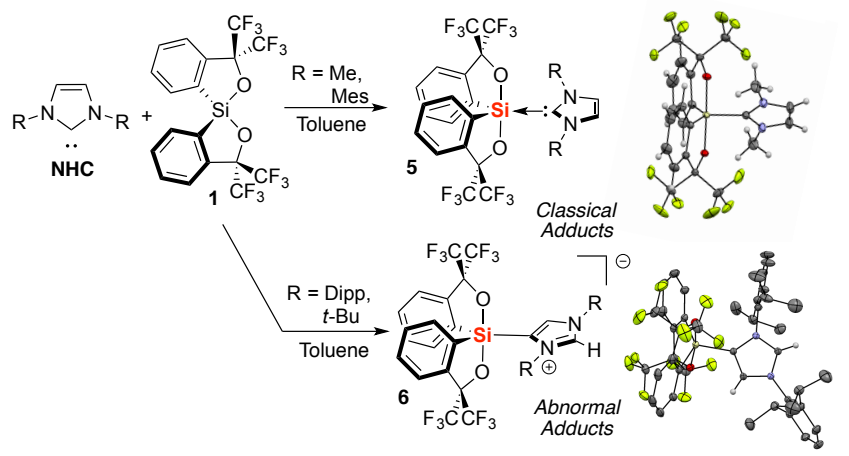

Scheme 3. Interaction between Martin's spirosilane 1 and NHCs

\subsection{Anionic NHC ligand featuring hypercoordinated silicon}

The abnormal adducts 6 have been later used as precursors for new anionic NHC carbene ligands possessing within their backbone a poorly coordinating anion. ${ }^{17}$ As a matter of fact, structures 6 are neutral species that could be seen as imidazolium rings attached to a silicate anion. Basically, the deprotonation of the positively charged heterocycles by using an appropriate base would lead to carbene ligands that can interfere with metals to form original organometallic complexes. From this perspective, the abnormal adducts 6 were cleanly deprotonated using $n$-butyllithium as a base, to be subsequently trapped with $\mathrm{Au}(\mathrm{I})$ or $\mathrm{Cu}(\mathrm{I})$ species affording complexes of type 7 and $\mathbf{8}$, respectively (Scheme 4). It is noteworthy that the anionic nature of the ligand and the presence of the lithium cation presumably favors the chloride dissociation from $\mathrm{ClAuPPh}_{3}$ to provide the corresponding neutral complexes. The strong $\sigma$ donor ability of these new anionic NHC ligands was confirmed by density-functional theory (DFT) calculations.
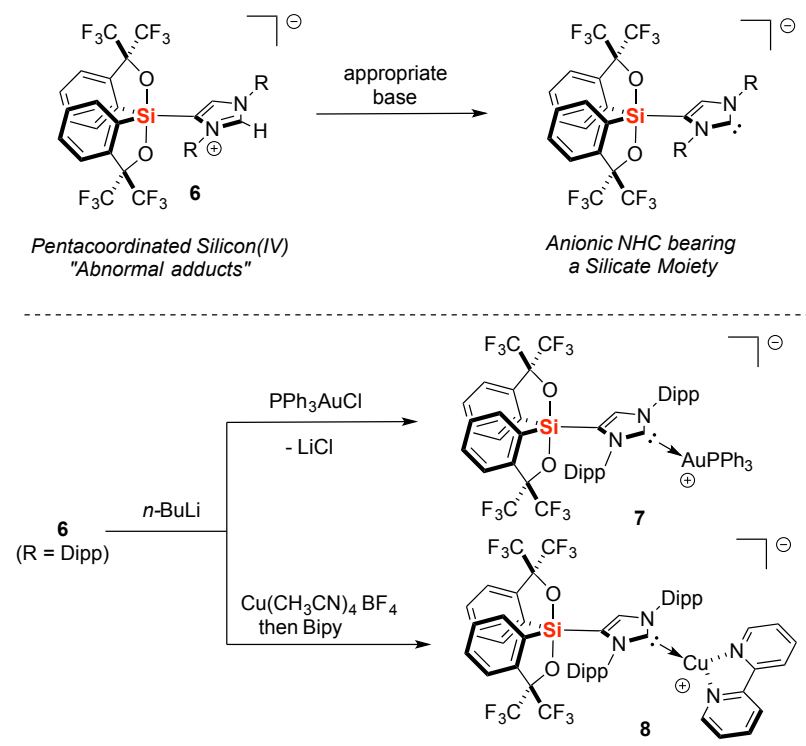

Scheme 4. Silicate-imidazolium zwitterions as precursors for anionic NHC ligands.

\subsection{Spirosilanes as Lewis acid partners in FLP chemistry}

As previously mentioned, the Martin's spirosilane $\mathbf{4}$ exhibits a FLP character when confronted to encumbered NHCs. The same trend was also observed with other hindered bases such as tert-butylphosphine and 2,2,6,6-tetramethylpiperidine since in both cases, no adducts are formed when they are in presence of silane $4 .{ }^{18}$ This behavior is similar to that of $\mathrm{B}\left(\mathrm{C}_{6} \mathrm{~F}_{5}\right)_{3}$, the most employed Lewis acid in FLP chemistry. ${ }^{19}$ For the sake of comparison, the Lewis acidity of Martin's spirosilane $\mathbf{4}$ was assessed using the Gutmann-Beckett parameter. ${ }^{20}$ Although the understanding of the Lewis acidity is very complex and depends on many parameters, this method based on the shift of triethylphopshine oxide in ${ }^{31} \mathrm{P}$ NMR spectroscopy represents a convenient way to roughly compare the electrophilicity of various species. The acceptor number of $\mathbf{4}$ was evaluated as $\mathrm{AN}=84.4$ which is slightly higher than the one calculated for $\mathrm{B}\left(\mathrm{C}_{6} \mathrm{~F}_{5}\right)_{3}$ ( $\mathrm{AN}$ $=81.4){ }^{21}$ 
Theoretically, the Lewis acid properties of the Martin's spirosilane $\mathbf{4}$ can be modulated by introducing substituents on the aromatic rings. For that purpose, a synthesis strategy of analogous structures of spirosilane $\mathbf{4}$ has been previously developed in our laboratory. ${ }^{22}$ It consists in the spirocyclization of functionalized hexafluorocumyl ligands that are readily available from the corresponding 2-brombenzoic acid derivatives (Scheme 5).

$$
\rightarrow \text { (thr }
$$

Scheme 5. Synthesis of Martin's spirosilane analogues.

With this method, the synthesis of a spirosilane 9 bearing one trifluoromethyl group on each aromatic ring was achieved. The presence of an electron-withdrawing group has a great effect on the electronic properties of the silicon atom and the acceptor number was calculated as $\mathrm{AN}=89.2$. That makes spirosilane 9 a remarkable Lewis acid particularly prone to reach hypervalency. The high electrophilicity of the $\mathrm{CF}_{3}$ derivative 9 was confirmed since a classical Lewis adduct $\mathbf{1 0}$ was formed in the presence of a bulky NHC (IPr) which has never been observed in the case of the simpler spirosilane 4 (Scheme 6). DFT calculations revealed that the presence of $\mathrm{CF}_{3}$ groups on the spirosilane increases the Gibbs free enthalpy of formation of the conventional adduct by at least $10 \mathrm{kcal}_{\mathrm{mol}}{ }^{-1}$.
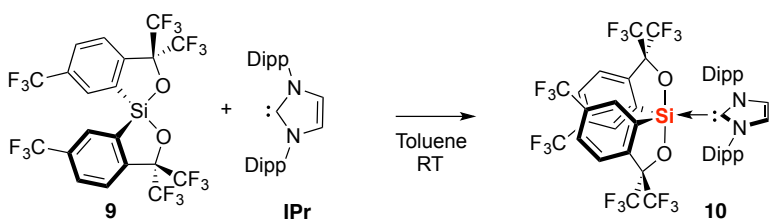

Scheme 6. Formation of classical Lewis adduct by reaction of spirosilane 9 with IPr

Although for the moment, Lewis acid partners $\mathbf{4}$ and even more Lewis acidic 9 proved to be inefficient for the activation of $\mathrm{H}_{2}$ and $\mathrm{CO}_{2}$, activation of formaldehyde was possible with the IPr NHC and tri-isopropylphosphine. In these cases, the zwitterionic adducts of type 11 could be isolated (Scheme 7 ).
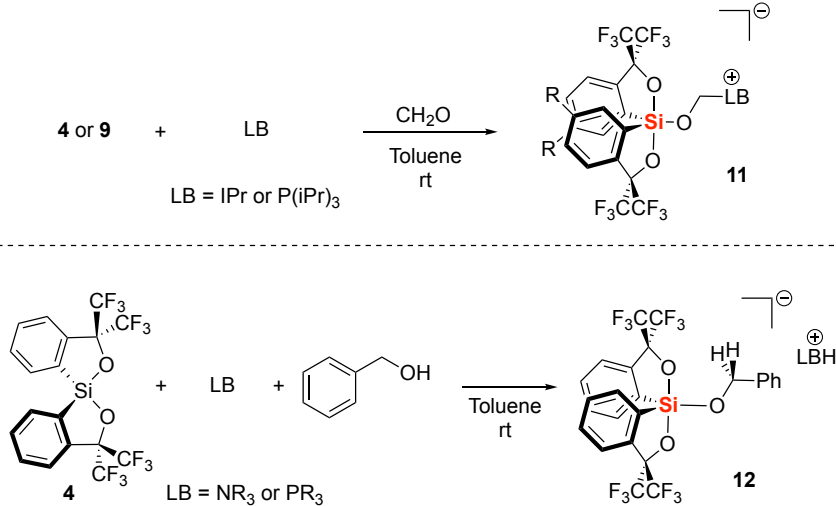

Scheme 7. Use of spirosilanes 4 and 9 in FLP chemistry

In addition, the Martin's spirosilane $\mathbf{4}$ could also be used for the activation of alcohols such as benzylic alcohol to form benzyloxysilicates 12 in the presence hindered phosphines or amines. On the ${ }^{1} H$ NMR spectrum, adducts 12 displayed $A B$ systems with a large splitting of the two diastereotopic benzylic protons that highlights the intrinsic chirality of the Martin's spirosilane at the NMR timescale. This interesting feature potentially opens the way for further asymmetric FLP transformations using chiral spirosilane analogues.

Louis Fensterbank obtained his $\mathrm{PhD}$ in 1993 at SUNY Stony Brook under the guidance of Scott Sieburth. After a lecturer position at the Université Pierre \& Marie Curie (UPMC), he was appointed in 1995 as a CNRS Chargé de Recherche with Max Malacria. In 2004, he became Professor at UPMC, now Sorbonne Université. His research interests concern the discovery of new molecular transformations relying on radical or organometallic processes and their applications to the

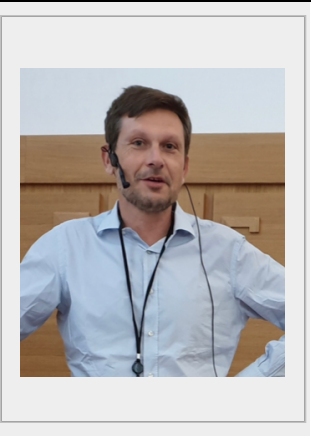
synthesis of substrates with relevant properties. Co-author of more than 220 publications, he has received several awards, notably the Silver Medal of CNRS in 2017 . He is also Fellow of the Royal Society of Chemistry

Gilles Lemière studied chemistry in Paris at the Université Pierre et Marie Curie (UPMC), where he obtained his $\mathrm{PhD}$ in 2008 under the supervision of Profs. Louis Fensterbank and Max Malacria. After his $\mathrm{PhD}$ on gold-catalysed new organic reactions, he joined the group of Prof. Jonathan Clayden in Manchester as a postdoctoral fellow to work on the total synthesis of natural compounds. In 2010 , he was appointed CNRS Researcher at the University of Nice in the group of Elisabet Dunach and moved in 2015 to Sorbonne Université, Paris. His research interests deal with the development of new metal- and acid-catalysed cycloisomerisation processes and silicon chemistry. 
Alexandre Millanvois received his Bachelor (UPMC) and master's degree at Sorbonne Université (ex UPMC) with honour. He is currently conducting his joint $\mathrm{PhD}$ under the supervision of Prof. Louis Fensterbank, Prof. Tan Choon Hong and Dr. Cyril Ollivier between Sorbonne Université and Nanyang Technological University (NTU). His current research interests are focused on the synthesis of new silicon based radical precursor and their application in asymmetric radical chemistry. order to generate functionalized alkyl radicals and particularly unstabilized primary ones (Scheme 8$).{ }^{28}$

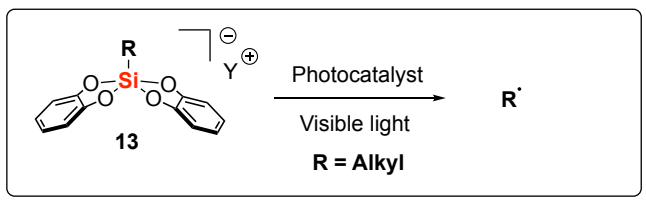

Scheme 8. Generation of alkyl radicals by photooxidation of alkyl biscatecholato silicates 13 under visible light irradiation

\subsection{Oxidation of alkyl bis-catecholato silicates through visible light photoredox catalysis: preliminary screenings}

Potassium alkyl bis-catecholato silicates 13 can be easily obtained by reaction of trialkoxysilanes with catechol and potassium methoxide in methanol. The presence of crown ether 18-crown-6 (18-C-6) stabilizes the hypercoordinated species ${ }^{3}$ so that a series of primary and secondary alkylsilicates with various functions can be prepared on a large scale and stored for a long time at room temperature with no significant degradation. Sodium silicates $\mathbf{1 3}$ are also accessible under the same conditions $(\mathrm{MeONa} / \mathrm{MeOH})$ but have shown a reduced stability, even in the presence of 15 -crown- $5 .{ }^{29}$ For cyclopentyl and tertbutyl silicates, the corresponding tetraethylammonium salts were obtained from trichlorosilanes (Scheme 9). ${ }^{30}$

\section{Bis-catecholato silicates as radical precursors}

\subsection{Oxidation of soft carbanions}

In the quest for new radical precursors, we engaged in the exploration of the oxidation of ate and hypercoordinated derivatives. The idea of such an approach originated from the very inspiring works of Kumada as $\mathrm{PI}$, featuring also the two prominent chemists: Kohei Tamao and the late Jun-ichi Yoshida, on the oxidation of pentafluorosilicates with copper(II) and some organic oxidants. ${ }^{23}$ We first tested this idea on alkyltrifluroborates and showed they could be smoothly oxidized by copper(II) salts or Dess-Martin periodinane to give alkyl radicals including primary ones. ${ }^{24}$ We then examined the reactivity of more soluble and user friendly bis-catecholato silicates synthesized by Cecil Frye ${ }^{25}$ and Robert Corriu ${ }^{26}$. We were encouraged to do so based on a series of works of Nishigaichi who reported the photoallylation of benzil-type derivatives and dicyanobenzene in moderate yields, but these reactions were limited to the generation of stabilized allyl and benzyl radicals. ${ }^{27}$ We therefore decided to prepare a series of bench stable alkyl bis-catecholato silicates 13 and to test them in photooxidative conditions under visible-light irradiation in

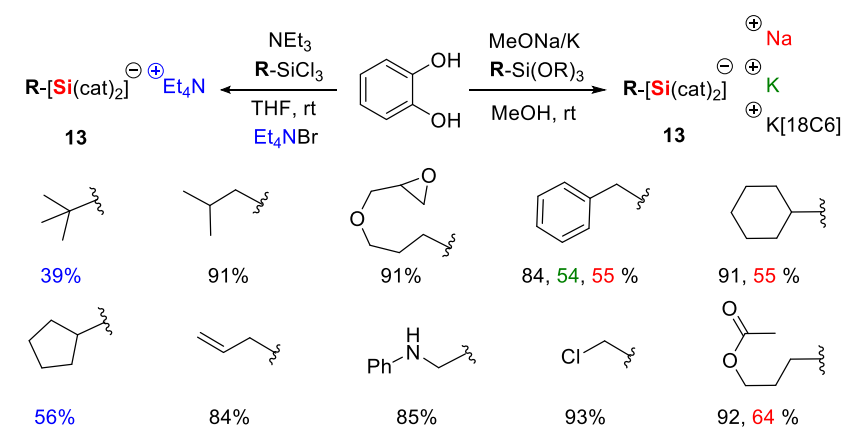

Scheme 9. Synthesis of functionalized sodium, potassium, ammonium and potassium[18-C-6] alkyl bis-catecholato silicates 13

The structures of the silicates 13 were studied by X-ray crystallography and showed a continuum between a quasisquare planar pyramidal (SP) geometry $(R=$ cyclohexyl, $\left.\mathrm{K}^{+}[18 \mathrm{C} 6]\right)$ and a trigonal bipyramidal (TBP) $(\mathrm{R}=$ cyclopentyl, $\mathrm{Et}_{4} \mathrm{~N}^{+}$), as already observed by Holmes ${ }^{31}$ (Scheme 10). The voltammetry that provided values $<+1.0 \mathrm{~V}$ vs. saturated calomel electrode (SCE) for both activated and non-activated alkylsilicates 13. These values were found to be lower than those of the corresponding carboxylates ${ }^{32}$ and trifluoroborates ${ }^{33}, 34$ and suggest that some photoexcited ruthenium or iridium-based photocatalysts can oxidize all the alkylsilicates. oxidation potentials of these silicates were determined by cyclic 

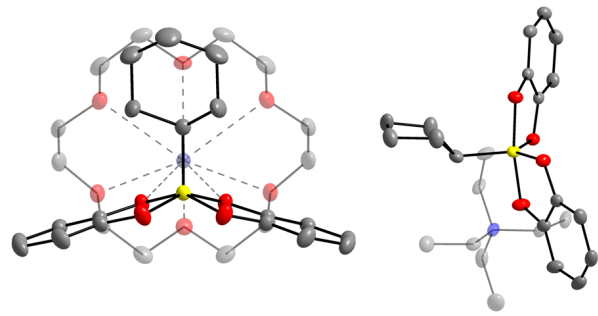

Scheme 10. X-ray crystallography of cyclohexyl (SP) and cyclopentyl (TBP) bis-catecholato silicates

Initially, benzylsilicate $\mathbf{1 4}$ was found to be capable of generating benzyl radical 15 under photooxidation conditions (Scheme 11). ${ }^{30}$ Based on a screening of photocatalysts including $\mathrm{Ru}(\mathrm{bpy})_{3}\left(\mathrm{PF}_{6}\right)_{2} \quad$ (bpy $=$ bipyridine) as well as $\operatorname{Ir}\left[\left(\mathrm{dF}\left(\mathrm{CF}_{3}\right) \mathrm{ppy}\right)_{2}(\mathrm{bpy})\right] \mathrm{PF}_{6}\left(\mathrm{dF}-\left(\mathrm{CF}_{3}\right) \mathrm{ppy}=2\right.$-(2,4-difluorophenyl)5-trifluoromethylpyridine), the latter revealed to be the most effective under blue light-emitting diodes (LEDs) irradiation leading to the 2,2,6,6-tetramethylpiperidinyl-oxide (TEMPO) adduct 16 in good yield. The low value of the oxidation potential of the benzylsilicate $\left(14, E_{o x}=+0.61 \mathrm{~V}\right.$ vs. SCE) fitted with the potential of the photoactivated catalyst $\left(R u^{\prime l} * / R u^{\prime}=+0.77 \mathrm{~V}\right.$ vs. SCE in $\mathrm{CH}_{3} \mathrm{CN}, \mathrm{Ir}^{\mathrm{II \prime *} / \mathrm{Ir}} \mathrm{I}^{\prime \prime}=+1.32 \mathrm{~V}$ vs. SCE in $\left.\mathrm{CH}_{3} \mathrm{CN}\right)$ and suggests that this one can oxidize the silicate. Stern-Volmer plot showed a linear relation between the intensity of the fluorescence and the concentration of quencher. Based on these experiments, a mechanism, where the photoactivated catalyst oxidizes the silicate and the benzyl radical $\mathbf{1 5}$ is trapped by TEMPO, was proposed (Scheme 11). The photocatalyst would be regenerated by the reduction of TEMPO (present in excess).

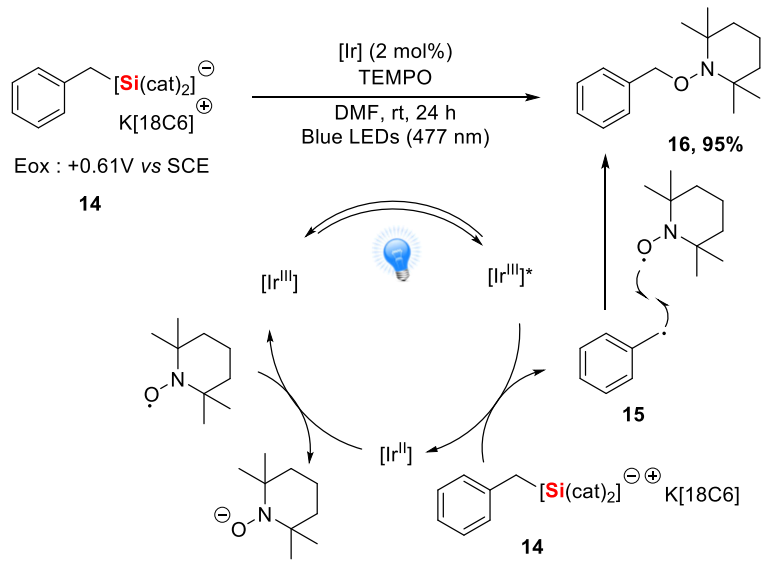

$[\mathrm{Ir}]=\operatorname{Ir}\left[\left(\mathrm{dF}\left(\mathrm{CF}_{3}\right) \mathrm{ppy}\right)_{2}(\mathrm{bpy})\right] \mathrm{PF}_{6}-\mathrm{E}_{1 / 2}\left(\mathrm{Ir}(\mathrm{III})^{*} / \mathrm{Ir}(\mathrm{II})\right)=+1.32 \mathrm{~V}$ vs SCE

Scheme 11. Visible-light photooxidation of benzyl bis-catecholato silicate 14, spin-trapping experiments with TEMPO and proposed mechanism

\subsection{Carbon-carbon bond formation by radical addition from alkyl bis-catecholato silicates}

The formation of carbon-carbon bond was explored by focusing mainly on the allylation of alkyl bis-catecholato silicates 13 with allylsulfones (Scheme 12). ${ }^{30}$ The range of substrates proved to be quite wide, from primary to tertiary alkylsilicates. We can mention in particular the generation of non-activated primary radicals, as well as new examples of aminomethylation and chloromethylation. A similar mechanism was proposed except that the radical adds to allylsulfone and after fragmentation, the sulfonyl radical participates to the regeneration of the photocatalyst, as already proved by MacMillan. ${ }^{35}$ As detailed below, radical chain mechanism in these allylations was excluded based on light/dark experiments and the determination of quantum yields. ${ }^{36}$

We next examined the reactivity of cyclohexyl silicate 18 toward various radical acceptors. The cyclohexyl radical 19 generated was then engaged in Giese-type reactions with various activated olefins. Vinylation can be reached by addition/fragmentation with vinylsulfones, bromides or chlorides, and alkynylation using an alkynylsulfone (Scheme 13).

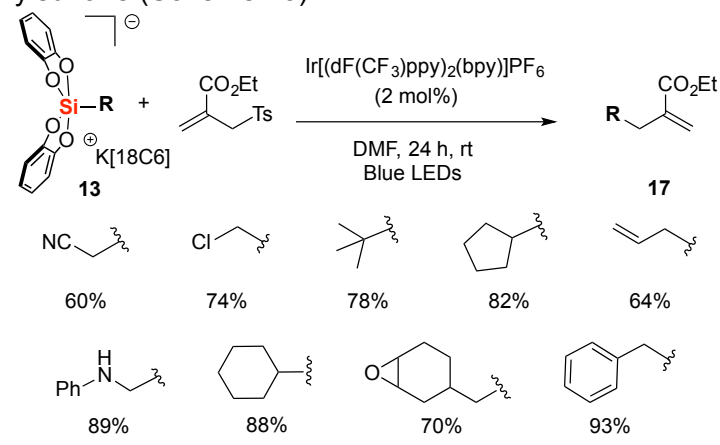

Scheme 12. Allylation reactions of a variety of functionalized silicates 13

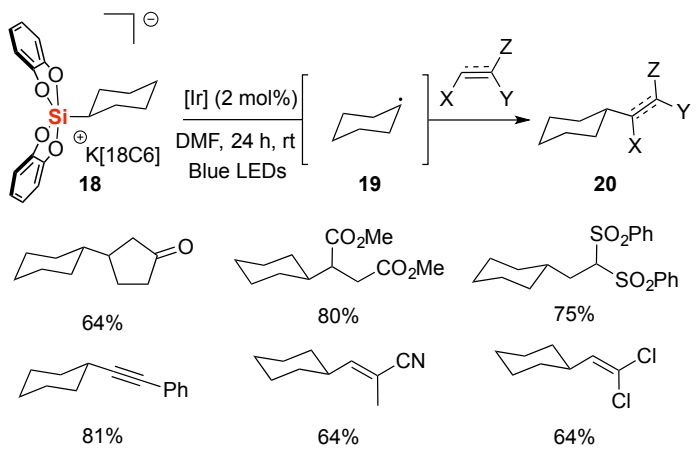

Scheme 13. Reactivity of cyclohexyl silicate 18 towards various radical acceptors

Computational studies on the oxidation of cyclohexyl biscatecholato silicate by the triplet state of $\operatorname{Ir}(\mathrm{III})-\mathrm{dF}\left(\mathrm{CF}_{3}\right)$ (triplet state) were carried out by Etienne Derat and showed a singleelectron transfer (SET) process from the catecholate ligand of the silicate to the metallic center of the photocatalyst. Comparison of the bond dissociation energy (BDE) of the substrates before and after electron transfer indicates that 
oxidation significantly weakens the $\mathrm{Si}-\mathrm{C}$ bond that undergoes cleavage. ${ }^{30}$ These DFT calculations fully validated the proposed mechanism.

As previously mentioned, the oxidation of the bis-catecholato silicates 13 has been accomplished using metal-based photocatalysts, and particularly rare and expensive polypyridine complexes of ruthenium or iridium. In order to provide greener reaction conditions, the reactivity of organic dyes as an alternative to metal complexes was explored. ${ }^{34,37}$ First, we found that only the more oxidant Fukuzumi acrididinium photocatalyst revealed to be the most efficient in spin trapping experiments with benzylsilicate 14 and no reaction was observed with Eosin and Fluorescein even if their oxidation potentials at the excited state also match with the silicate. ${ }^{34}$ In 2012, Adachi et al. described a new carbazoyl dicyanobenzene complex, 1,2,3,5tetrakis(carbazol-9-yl)-4,6-dicyanobenzene (4CzIPN), which demonstrated a high photoluminescence quantum yield $(94.6 \%)$ and a long life-time $(5.1 \mu \mathrm{s})$ at the excited state. ${ }^{38}$ Later, Zhang measured the oxidative potentials of $4 \mathrm{CZIPN}$ and of related structures. He was also the first one to apply these carbazole derivatives as photocatalysts for the photooxidation of stabilized carboxylate and trifluoroborate. ${ }^{39}$ The potential of $4 \mathrm{CzIPN}$ at the excited state was recently revised by Waser at $+1.59 \mathrm{~V}$ vs. SCE. ${ }^{40}$ Based on these physico-chemical data and not surprisingly, benzylsilicate $\mathbf{1 4}$ gave the TEMPO adduct 16 in $94 \%$ yield with a catalytic loading in 4 CzIPN of only $1 \mathrm{~mol} \%$ (Scheme 14). Vinylation, allylation, alkynylation and Giese-type adducts 21 were also obtained in good yields with a variety of alkylsilicates (Scheme 15).

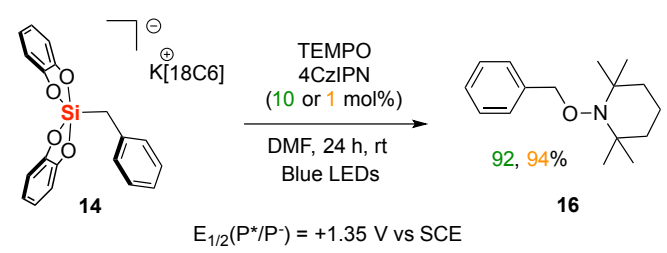

Scheme 14. Photooxidation of benzyl bis-catecholato silicate 14 with the organic dye $4 \mathrm{CzIPN}$

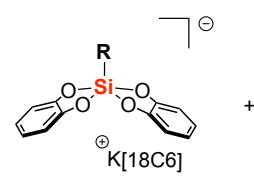

13<smiles>ClC(Cl)=CC1CCCC1</smiles>

$70 \%$

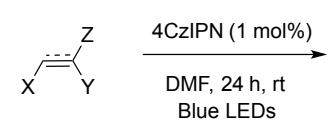

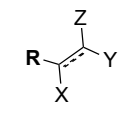

21<smiles>C=C(CCP(=O)(c1ccccc1)c1ccccc1)C(=O)OCC</smiles><smiles>C=C(CC(C)(C)C)C(=O)OCC</smiles>
$94 \%$<smiles></smiles><smiles>CCCCC(CC(=O)OC)C1CCCCC1</smiles>

Scheme 15 . Photooxidation of alkylsilicates 13 by 4 CzIPN with various $C$ radical acceptors
A new methodology of radical carbonylation of alkyl biscatecholato silicates 13 under photocatalyzed oxidation conditions was developed in collaboration with the group of Illhong Ryu and Takahide Fukuyama from Osaka Prefecture University and could be implemented in multicomponent reactions. Thus, alkyl radicals generated by photooxidation of the corresponding organosilicates with $4 \mathrm{CzIPN}$, participate in radical carbonylation with carbon monoxide (CO) in the presence of electron-deficient alkenes as radical acceptors, providing a series of unsymmetrical ketones 22 and 23 via an acyl radical intermediate. These optimized conditions were applied to a variety of alkylsilicates. The carbonylation of primary, secondary and tertiary radicals worked well and led to the corresponding ketones in good yields (Scheme 16). Gratifyingly, we tested different alkenes as radical acceptors. For instance, $\alpha, \beta$-unsaturated ketones participated in these three-component to afford 1,4-diketones. Transformations with $\mathrm{N}, \mathrm{N}$-dimethyl acrylamide and acrylonitrile were equally effective as well as those carried out with an allylsulfone. "Light-dark" experiments conducted in the absence of $\mathrm{CO}$ and quantum yield measurements supported a catalytic photoredox process and not a radical chain pathway. In this case, a SET oxidation of the silicate by the excited photocatalyst results in the formation of the alkyl radical that adds to $\mathrm{CO}$ to form an acyl radical. The latter then adds to the radical acceptor.

$$
\text { (2) }
$$

Scheme 16. Three-component radical carbonylation reactions of alkyl biscatecholato silicates $\mathbf{1 3}$ for the synthesis of unsymmetrical ketones $\mathbf{2 2}$ and $\mathbf{2 3}$

In the presence of an amine and carbon tetrachloride, the transient acyl radical generates an acyl chloride through chlorine abstraction from $\mathrm{CCl}_{4}$ and leads this time to a variety of amides 24 with yields ranging from 34 to $89 \%$. An amine with a potentially reactive alcohol only furnishes the corresponding amide and no trace of ester was observed (Scheme 17). ${ }^{41}$ 


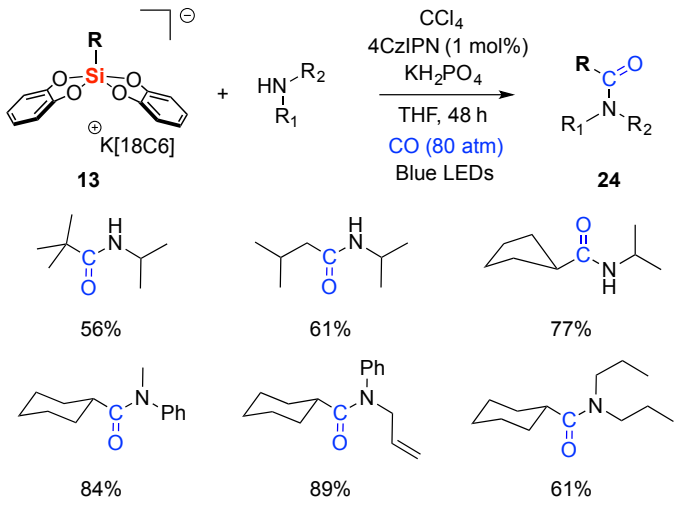

Scheme 17. Synthesis of aliphatic amides 24 by radical carbonylation starting from alkyl bis-catecholato silicates 13

\subsection{Cross-coupling reactions by dual photoredox/Nickel catalysis}

A particularly attractive field concerns dual photoredox/organometallic catalysis. Initially developed through photoreductive processes,$^{42}$ the possibility of coupling aromatic electrophiles with radicals, generated by photooxidation, thanks to nickel complexes was recently demonstrated. ${ }^{43}$ This type of coupling was first reported by the groups of Molander, MacMillan and Doyle with a primary or a secondary radical obtained respectively from activated trifluoroborates or carboxylic acid derivatives or methylamines as easy oxidation substrates. ${ }^{44,45}$ We wished to examine the possibility of introducing silicates in these cross couplings and notably what would be the benefits of their use. ${ }^{37,46}$ When treated with $\mathrm{Ni}(\mathrm{COD})_{2} /$ iridium photocatalyst or $\mathrm{NiCl}_{2} \cdot \mathrm{dme} / 4 \mathrm{CzIPN}$ catalytic systems, silicates 13 could be coupled with electron poor and electron rich (hetero)arylbromides and gave the cross-coupling product $\mathbf{2 5}$ with benzyl, allyl, $\alpha$-amino methyl and secondary radicals as well as proved successful with unstabilized primary radicals. These results revealed that silicates are partners of choice in the dual catalysis processes, as shown also by the Molander group. ${ }^{47}$ The scope of the transformation is broad and the process is tolerant with various functions, such as a pinacol alkylboronate function on the aryl ring. The $\mathrm{NiCl}_{2} / 4 \mathrm{CzIPN}$ dual catalysis conditions allowed to couple both ethylenic bromides and chlorides with acetoxypropyl bis-catecholato silicate $\mathbf{2 6}$ with a high diastereoselectivity (Scheme 19, Eq. 1). ${ }^{37}$ Finally, gemdichlorostyrenes were reacted with primary and secondary (non)activated alkylsilicates 13 (such as 14, R = benzyl) and provided exclusively the corresponding monoalkylated cross coupling (Z)-styrylchloride products (28) (Scheme 19, Eq. 2). ${ }^{37,29}$
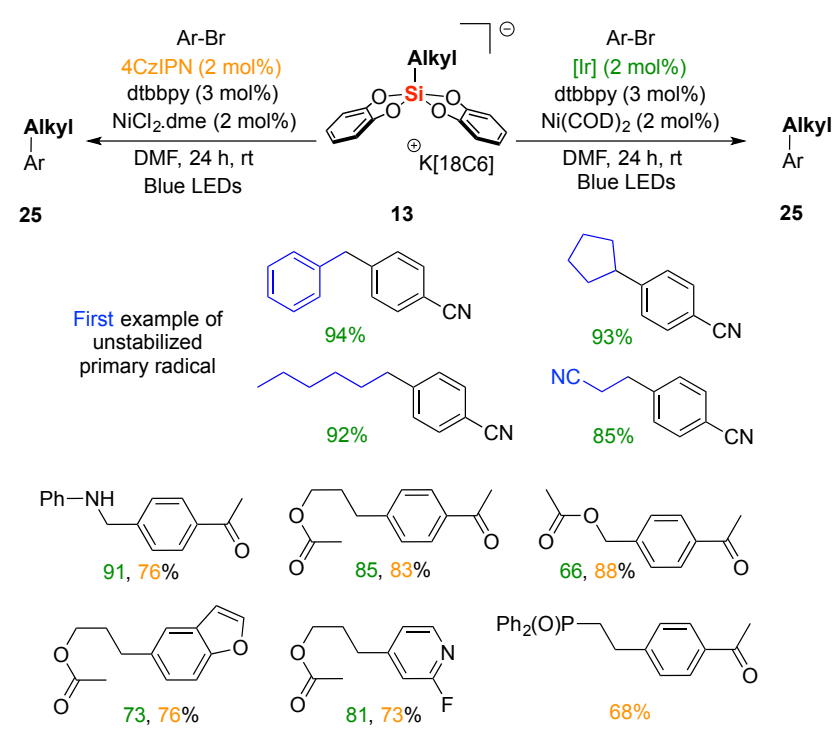

Scheme 18. Cross coupling reactions of silicates 13 with various arylbromides

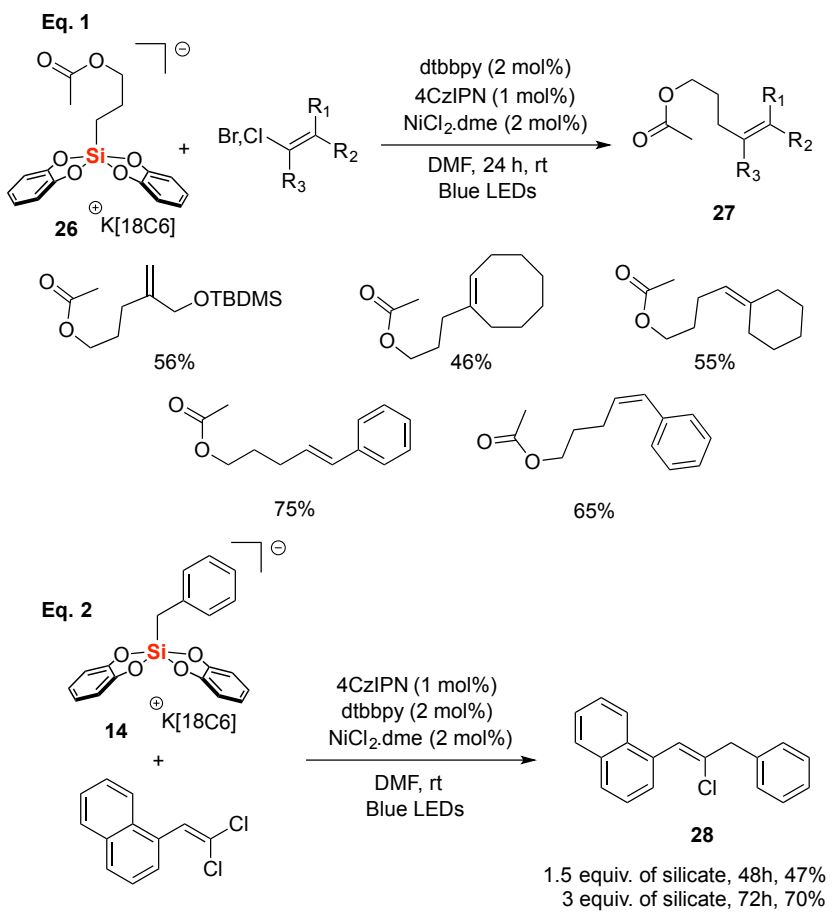

Scheme 19. Reaction of bis-catecholato silicates 26 and 14 with alkenyl halides

After developing an efficient photoredox/nickel dual catalytic process for $\mathrm{C}\left(s p^{3}\right)-\mathrm{C}\left(s p^{2}\right)$ coupling, alkylsilicates 13 (such as $\mathbf{2 9}$, $\mathrm{R}=\mathrm{n}$-hexyl) were involved in cross-coupling reactions with alkyl halides such as 4-bromobutyrate to create $\mathrm{C}\left(s p^{3}\right)-\mathrm{C}\left(s p^{3}\right)$ bonds. ${ }^{48}$ The corresponding products $(\mathbf{3 0})$ were obtained in moderate yields, either from primary and also secondary alkylsilicates, along with the homocoupling product (31) of the 
alkyl halide. The mechanism is still under discussion and needs to be clarified (Scheme 20).

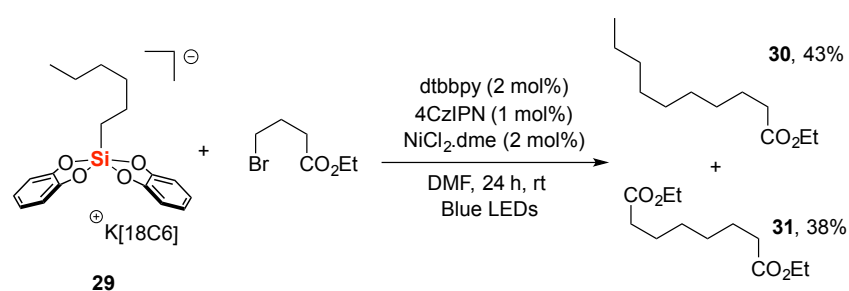

Scheme 20. Cross-coupling reactions between $n$-hexyl bis-catecholato silicate 29 and 4-bromobutyrate

Finally, we were interested in the reactivity of silicates 13 towards acyl chlorides in order to obtain benzyl and alkyl ketones 32, which are of great interest in fragrance and flavors industry, and more generally, as synthetic intermediates. ${ }^{49}$ Upon treatment with a complex of iridium as photocatalyst and $\mathrm{NiCl}_{2}$.dme under irradiation with blue LEDs, an alkylsilicate 13 can be coupled to an acyl chloride as electrophile to give the expected ketones 32 (Scheme 21). Several silicates 13 were then tested under these conditions. Cyclohexyl, norbornyl and mainly the activated silicates such as the methoxymethylene and benzyl derivatives were able to provide the desired product and notably highly enolizable ketones. The nature of the acyl chloride partner also influenced this coupling since both electron-rich benzoyl chlorides and alkyl ones afforded the corresponding ketones in good yields, including variously substituted dibenzyl ketones (Scheme 21). In collaboration with Michaël Tatoulian, Stéphanie Ognier and Mengxue Zhang from Institut Pierre-Gilles de Gennes in Paris, we used miniaturized flow reactors to accelerate this photooxidative process, without increasing the yield though. Only 20 minutes are necessary to obtain the cross-coupling product $\mathbf{3 3}$ from benzylsilicate $\mathbf{1 4}$ and benzoyl chloride whereas 24 hours are necessary under normal circumstances (Scheme 22).

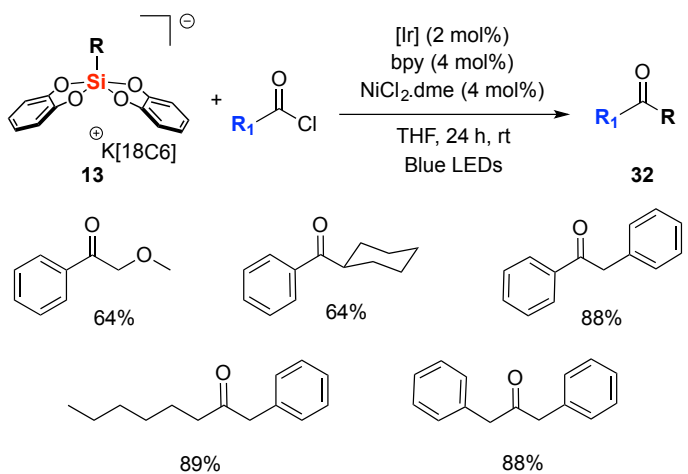

Scheme 21. Acylation of alkyl bis-catecholato silicates 13 via dual nickel photocatalysis

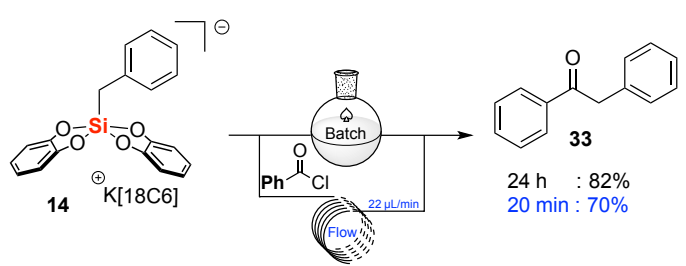

Scheme 22. Continuous flow vs. batch processing

\section{Perspectives}

This survey of our recent works involving hypercoordinated silicon derivatives illustrates, if it was still necessary, that this class of intriguing compounds offer unique opportunities in organic synthesis. At the origin of the described reactivities in this account, lays the Lewis acidity of a silicon center bearing electronegative ligands such as a catecholate ${ }^{50}$ or the dianion of hexafluorocumyl alcohol, Martin's, which formally welcomes a nucleophilic addition to generate selectively pentavalent species. The formally resulting bis-catecholato silicates have proven to be excellent precursors of unstabilized alkyl radicals in a series of radical sequences. They position therefore themselves as reagents of choice for the introduction of $\mathrm{Csp} p^{3}$-rich fragments on (hetero)aryl platforms through dual Ni/photoredox catalysis which is highly praised in medicinal chemistry ("escape from the flatland"). The realm of applications of these reagents is rapidly expanding as illustrated by the contributions of several groups. ${ }^{51}$ Martin's spirosilane 4 has been known for more than 40 years but rarely considered as an alternative to the highly encountered $\mathrm{B}\left(\mathrm{C}_{6} \mathrm{~F}_{5}\right)_{3}$ Lewis acids. Our preliminary works have delivered valuable elements of reactivity that augur well for more sophisticated applications. Interestingly, alkylsilicates obtained by Kano's group from $\mathbf{4}$ also proved to be sources of radicals. Despite their higher oxidation potentials $(>1.0 \mathrm{~V})$, they also give an access to C-centered alkyl radicals, including the methyl radical. ${ }^{52}$ The oxidation mechanism in that case is distinct since it is the C-Si bond that is directly oxidized.

Future research directions along these lines will involve the tuning of the silicon ligands ${ }^{22}$ and the study of their effects. Notably, how can their modification by the substitution of the aromatic groups can improve the oxidation process and give access to sp2-radicals ${ }^{53}$ for instance. Application to radical cascades that open a straightforward access to molecular complexity are envisioned.

\section{Acknowledgements}

We wish to warmly acknowledge all our collaborators whose works were cited in this manuscript. We also thank Sorbonne Université, CNRS, PSL University, ANR-17-CE07-0018 HyperSiLight.

Keywords: Silicon $\bullet$ Lewis acid $\bullet$ silicate $\cdot$ photoredox $\bullet$ radical 
Entry for the Table of Contents (Please choose one layout)

\section{PERSONAL ACCOUNT}

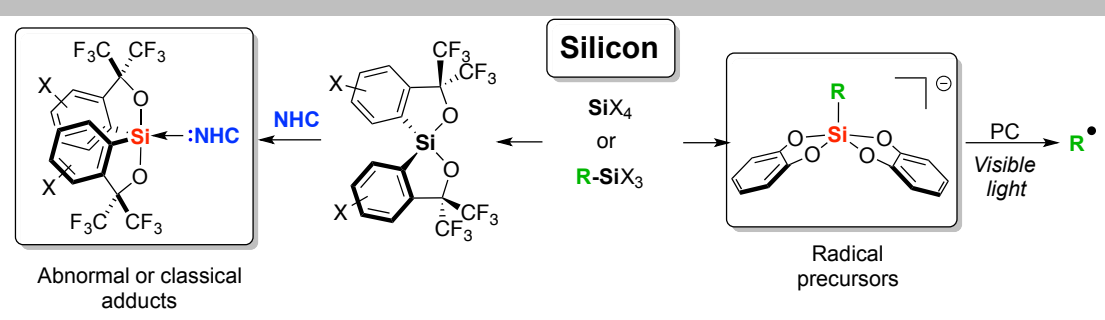

Silicon at its best! Less than ten years of acquaintance with hypercoordinated silicon derivatives in our lab is described in this account. Martin's spirosilane derivatives open new opportunities as ligands and as agents for the activation of small molecules and bis-catecholato silicates have proven to be exquisite radical precursors in photoredox conditions for broad synthetic applications.
Gilles Lemière*, Alexandre Millanvois ${ }^{[a]}$, Cyril Ollivier*, and Louis Fensterbank*

Page No. - Page No.

A Parisian Vision of the Chemistry of Hypercoordinated Silicon Derivatives

\section{References}

${ }^{1}$ S. N. Tandura, M. G. Voronkov, N. V. Alekseev, Top. Curr. Chem. 1986, 131, 99-189.

${ }^{2}$ R. R. Holmes, Chem. Rev. 1996, 96, 927-950.

${ }^{3}$ C. Chuit, R. J. P. Corriu, C. Reye, J. C. Young, Chem. Rev. 1993, 93, 1371-1448.

${ }^{4}$ For recent articles on the chemistry of hypercoordinated organosilicon compounds, see: a) G. Singh, G. Kaur, J. Singh, Inorg. Chem. Commun. 2018, 88, 11-20. b) A. S. Soldatenko, I. V. Sterkhova, N. F. Lazareva, J. Organomet. Chem. 2019, 903, 120997-121004. c) D. Mu, W. Yuan, S. Chen, N. Wang, B. Yang, L. You, B. Zu, P. Yu, C. He, J. Am. Chem. Soc. 2020, 142, 13459-1348.

${ }^{5}$ S. Rendler, M. Oestreich, Synthesis 2005, 1727-1747.

${ }^{6}$ D. Kost, I. Kalikhman in PATAl's Chemistry of Functional Groups, John Wiley \& Sons 2009, 1-107.

${ }^{7}$ S. M. Sieburth, L. Fensterbank, J. Org. Chem. 1993, 58, 6314-6318.

${ }^{8}$ S. M. Sieburth, L. Fensterbank, J. Org. Chem. 1992, 57, 5279-5281.

${ }^{9}$ S. Bogen, M. Gulea, L. Fensterbank, M. Malacria, J. Org. Chem. 1999, 64, 4920-4925 and references therein.

${ }^{10}$ N. Puljic, M. Albert, A.-L. Dhimane, L. Fensterbank, E. Lacôte, M. Malacria, Helv. Chim. Acta 2006, 89, 2297-2305.

${ }^{11}$ C. Blaszykowski, C. Brancour, A.-L. Dhimane, L. Fensterbank, M. Malacria, Eur. J. Org. Chem. 2009, 1674-1678.

${ }^{12}$ E. F. Perozzi, J. C. Martin, J. Am. Chem. Soc. 1979, 101, 1591-1593.

${ }^{13}$ a) W. H. Stevenson III, S. Wilson, J. C. Martin, W. B. Farnham, J. Am. Chem. Soc. 1985, 107, 6340-6352; b) D. A. Dixon, W. R. Hertler, D. B. Chase, W. B. Farnham, F. Davidson, Inorg. Chem. 1988, 27, 4012-4018; c) S. K. Chopra, J. C. Martin, J. Am. Chem. Soc. 1990, 112, 5342-5343; d) N. Kano, H. Miyake, K. Sasaki, T. Kawashima, N. Mizorogi, S. Nagase, Nat Chem 2010, 2, 112-116.

${ }^{14}$ H. Lenormand, J.-P. Goddard, L. Fensterbank, Org. Lett. 2013, 15, 748-751.

${ }^{15}$ H. Ruppert, L. Greb, Organometallics 2020,39, 4340-4349..

${ }^{16}$ F. Medici, G. Gontard, E. Derat, G. Lemière, L. Fensterbank, Organometallics 2018, 37, 517-520.

${ }^{17}$ For review on anionic $N$-Heterocyclic Carbenes, see: A. Nasr, A. Winkler, M. Tamm, Coord. Chem. Rev. 2016, 316, 68-124.

${ }^{18}$ F. Medici, J. Maury, G. Lemière, L. Fensterbank, Chem. Eur. J. 2019, 25, 9438-9442.

${ }^{19}$ For leading reviews, see: a) D. W. Stephan, Acc. Chem. Res. 2015, 48, 306-316; b) D. W. Stephan, G. Erker, Angew. Chem. Int. Ed. 2015, 54, 6400-6441; c) D. W. Stephan, J. Am. Chem. Soc. 2015, 137, 10018-10032; d) J. Paradies, Angew. Chem. Int. Ed. 2014, 53, $3552-$ 3557.

${ }^{20}$ a) M. A. Beckett, G. C. Strickland, J. R. Holland, K. S. Varma, Polymer 1996, 37, 4629-4631; b) V. Gutmann, Coord. Chem. Rev. 1976, 18, 225-255.

${ }^{21}$ A. Ashley, T. J. Herrington, G. G. Wildgoose, H. Zaher, A. L. Thompson, N. H. Rees, T. Krämer, D. O’Hare, J. Am. Chem, Soc. 2011, 133, $14727-14740$

${ }^{22}$ H. Lenormand, V. Corcé, G. Sorin, C. Chhun, L.-M. Chamoreau, L. Krim, E.-L. Zins, J.-P. Goddard, L. Fensterbank, J. Org. Chem. 2015, 80, 3280-3288.

${ }^{23}$ J.-i. Yoshida, K. Tamao, H. Yamamoto, T. Kakui, H. Matsumoto, M. Takahashi, A. Kurita, M. Murata, M. Kumada, Organometallics 1982, 1 , 355-368.

${ }^{24}$ G. Sorin, R. Martinez Mallorquin, Y. Contie, A. Baralle, M. Malacria, J.-P.Goddard, L. Fensterbank, Angew. Chem. Int. Ed. 2010, 49, 87218723.

${ }^{25}$ C. L. Frye, J. Am. Chem. Soc. 1964, 86, 3170-3171.

${ }^{26}$ A. Boudin, G. Cerveau, C. Chuit, R. J. P. Corriu, C. Reye, Bull. Chem. Soc. Jpn. 1988, 61, 101-106

${ }^{27}$ a) Y. Nishigaichi, A. Suzuki, T. Saito, A. Takuwa, Tetrahedron Lett. 2005, 46, 5149-5151; b) Y. Nishigaichi, A. Suzuki, A. Takuwa, Tetrahedron Lett. 2007, 48, 211-214; c) D. Matsuoka, Y. Nishigaichi, Chem. Lett. 2014, 43, 559-561; d) D. Matsuoka, Y. Nishigaichi, Chem. Lett. 2015, 44, 163-165. 
${ }^{28}$ V. Corcé, C. Lévêque, C. Ollivier, L. Fensterbank in Science of Synthesis: Photocatalysis in Organic Synthesis (Ed.: B. König), Thieme Stuttgart, 2019, pp. 427-466.

${ }^{29}$ M. Abdellaoui, A. Millanvois, E. Levernier, C. Ollivier, L. Fensterbank, Synlett 2021, 32, doi: 10.1055/a-1374-9384.

${ }^{30}$ V. Corcé, L.-M. Chamoreau, E. Derat, J.-P. Goddard, C. Ollivier, L. Fensterbank, Angew.Chem. Int. Ed. 2015, 54, 11414-11418; Angew. Chem. 2015, 127, 11576-11580.

${ }^{31}$ R. R. Holmes, Chem. Rev. 1990, 90, 17-31.

${ }^{32}$ H. G. Roth, N. A. Romero, D. A. Nicewicz, Synlett 2016, 27, 714-723.

${ }^{33}$ J. Suzuki, M. Tanigawa, S. Inagi, T. Fuchigami, ChemElectroChem 2016, 3, 2078-2083

${ }^{34}$ L. Chenneberg, C. Lévêque, V. Corcé, A. Baralle, J.-P. Goddard, C. Ollivier, L. Fensterbank, Synlett 2016, 27, 731-735.

${ }^{35}$ A. Noble, D. W. C. MacMillan, J. Am. Chem. Soc. 2014, 136,11602-11605.

${ }^{36}$ A. Cartier, E. Levernier, V. Corcé, T. Fukuyama, A.-L. Dhimane, C. Ollivier, I. Ryu, L. Fensterbank, Angew. Chem. Int. Ed. 2019, 58, 17891793; Angew. Chem. Int. Ed. 2019, 131, 1803-1807.

${ }^{37}$ C. Lévêque, L. Chenneberg, V. Corcé, C. Ollivier, L. Fensterbank, Chem. Comm. 2016, 52, 9877-9880.

${ }^{38}$ H. Uoyama, K. Goushi, K. Shizu, H. Nomura and C. Adachi, Nature 2012, 492, 234-240.

39 J. Luo and J. Zhang, ACS Catal. 2016, 6, 873-877.

${ }^{40}$ F. Le Vaillant, M. Garreau, S. Nicolai, G. Gryn'ova, C. Corminboeuf, J. Waser, Chem. Sci. 2018, 9, 5883-5889

${ }^{41}$ A. Cartier, E. Levernier, A. - L. Dhimane, T. Fukuyama, C. Ollivier, I. Ryu, L. Fensterbank, Adv. Synth. Catal. 2020, 362, 2254-2259.

42 a) D. Kalyani, K. B. McMurtrey, S. R. Neufeldt, M. S. Sanford, J. Am. Chem. Soc. 2011, 133, 18566-18569; b) J. Twilton, C. C. Le, P. Zhang, M. H. Shaw, R. W. Evans, D. W. C. MacMillan, Nature Reviews Chemistry 2017, 1, 1-19.

${ }^{43}$ C. Lévêque, C. Ollivier, F. Fensterbank, in Nickel Catalysis in Organic Synthesis (Ed.: S. Ogoshi), Wiley 2020, pp $151-181$.

44 J. C. Tellis, D. N. Primer, G. A. Molander, Science 2014, 345, 433-436.

${ }^{45}$ Z. Zuo, D. Ahneman, L. Chu, J. Terrett, A. G. Doyle, D. W. C. MacMillan, Science 2014, 345, 437-440.

${ }^{46}$ C. Lévêque, L. Chennenberg, V. Corcé, J.-P. Goddard, C. Ollivier, L. Fensterbank, Org. Chem. Front. 2016, 3, $462-465$.

${ }^{47}$ a) M. Jouffroy, D. N. Primer, G. A. Molander, J. Am. Chem. Soc. 2016, 138, 475-478; b) J. K. Matsui, S. B. Lang, D. R. Heitz, G. A. Molander, ACS Catal. 2017, 7, 2563-2575.

${ }^{48}$ C. Lévêque, V. Corcé, L. Chenneberg, C. Ollivier, L. Fensterbank, Eur. J. Org. Chem. 2017, $2118-2121$.

${ }^{49}$ E. Levernier, V. Corcé, L.-M. Rakotoarison, A. Smith, M. Zhang, S. Ognier, M. Tatoulian, C. Ollivier, L. Fensterbank, Org. Chem. Front. 2019, 6, 1378-1382.

${ }^{50}$ a) A. L. Liberman-Martin, R. G. Bergman, T. D. Tilley, J. Am. Chem. Soc. 2015, 137, 5328-5331; b) R. Maskey, M. Schädler, C. Legler, L. Greb, Angew. Chem. Int. Ed. 2018, 57, 1717-1720, Angew. Chem. 2018, 130, 1733-1736; c) D. Hartmann, M. Schadler, L. Greb, Chem Sci 2019, 10, 7379-7388.

${ }^{51}$ a) K. D. Raynor, G. D. May, U. K. Bandarage, M. J. Boyd, J. Org. Chem. 2018, 83, 1551-1557; b) T. Guo, X. Liu, Y. Fang, X. Jin, Y. Yang, Y. Li, B. Chen, M. Ouyang, Adv. Synth. Catal. 2018, 360, 4457-4650; c) A. García-Domínguez, R. Mondal, C. Nevado, Angew. Chem. Int. Ed. 2019, 58, 2-7; Angew. Chem. 2019, 131, 12414-12418; d) S. T. J. Cullen, G. K. Friestad, Org. Lett., 2019, 21, 8290-8294; e) Z.-J. Wang, S. Zheng, J. K. Matsui, Z. Lu, G. A. Molander, Chem. Sci., 2019, 10, 4389-4393.

${ }^{2}$ a) G. Ikarashi, T. Morofuji, N. Kano, Chem. Commun. 2020, 56, 10006-10009; b) T. Morofuji, Y. Matsui, M. Ohno, G. Ikarashi, N. Kano, Chem. Eur. J. 2021 DOI https://doi.org/10.1002/chem.202005300.

53 Levernier, E.; Jaoudi, K.; Zhang, H.-R.; Corcé, V.; Bernard, A.; Gontard, G.; Troufflard, C.; Grimaud, L.; Derat, E.; Ollivier, C. submitted. 